\title{
Hepatitis B viral mutants and their relevance to the Canadian health care system
}

\author{
Gerald Y Minuk MD FRCPC
}

\begin{abstract}
GY Minuk. Hepatitis B viral mutants and their relevance to the Canadian health care system. Can J Gastroenterol 2002;16(1):45-54.

Over the past 10 years, an increasing number of mutations in the hepatitis B virus genome have been described. While the majority of these mutations appear to be 'silent' or not clinically relevant, some have been described in association with increased severity of disease (core and basic core promoter mutations), evasion of immunological surveillance ( $\mathrm{S}$ escape mutants), hepatocellular carcinogenesis (X mutants) and resistance to antiviral agents (DNA polymerase mutations). The molecular events and the clinical consequences thereof are reviewed.
\end{abstract}

Key Words: Hepatitis B virus

$\prod$ m here are few areas of medicine that can generate as much confusion and despair in the minds of medical practitioners as hepatitis $B$ viral (HBV) infections. A large part of that response stems from the array of serological tests associated with the virus and, to some extent, the varying interpretation of the results in the context of the clinical scenario and other findings. Thus, it was with much relief that physicians learned in the early 1980s of the development of a vaccine for HBV that held promise to eradicate the virus and thereby render the need to understand HBV only for historical interest. More recently, successes with antiviral therapies in the 1990s have reinforced that initial optimism. Did both advances provide the medical commu-

\section{Souches mutantes du virus de l'hépatite B et leur pertinence pour le système de soins de santé canadien}

RÉSUMÉ : Depuis une dizaine d'années, le nombre de mutations affectant le génome du virus de l'hépatite B (HBV) augmente. Bien que la majorité de ces mutations semblent " silencieuses " et non pertinentes sur le plan clinique, certaines ont été décrites en lien avec une aggravation de la maladie (mutations du noyau et de son précurseur), évasion de la surveillance immunologique (mutants $\mathrm{S}$ ), carcinogenèse hépatocellulaire (mutants $\mathrm{X}$ ) et résistance aux antiviraux (mutations de la polymérase de l'ADN). On passe ici en revue les phénomènes moléculaires et leurs conséquences cliniques.

nity with false hopes? Are the days for this virus truly numbered, or will physicians continue to manage HBV-infected individuals for generations to come? Unfortunately, the ever-increasing number of mutations described in response to immunoprophylaxis and antiviral therapies raises the possibility that HBV will not disappear but will continue to cause significant morbidity and mortality in a large percentage of the world's population for at least the foreseeable future.

The principal purpose of this review is to provide medical practitioners with an account of the current situation in the battle against $\mathrm{HBV}$ and, specifically, to determine whether there is need for concern regarding the mutations

Liver Diseases Unit, University of Manitoba, Winnipeg, Manitoba

Correspondence and reprints: Dr GY Minuk, Director, Liver Diseases Unit, Health Sciences Centre, John Buhler Research Centre, Winnipeg,

Manitoba R3E 3P4. Telephone 204-789-3204, fax 204-789-3971, e-mail gminuk@cc.umanitoba.ca

Received for publication October 10, 2000. Accepted January 15, 2001 
or 'counterattack' the virus has developed in its struggle for survival. However, any such account must begin with an attempt to put the clinical problem in its proper perspective, a working understanding of the replicative cycle of the wild-type (nonmutated) virus and an outline of our present interpretations of HBV serology.

\section{CLINICAL PROBLEM}

The prevalence of HBV varies between $0.1 \%$ and $15 \%$ in different parts of the world (1). Because prevalence rates are highest in areas where the world's population is greatest (eg, Southeast Asia), the overall prevalence has been estimated to be approximately $5 \%$, or 350 million individuals. Somewhat different concerns exist regarding the natural history of HBV infections in children and adults. Whereas their HBV infections tend to be mild and often subclinical, children's propensity to develop chronic HBV carrier states (infections that persist beyond six months) is high (90\% in newborns and $15 \%$ to $30 \%$ in adolescents). On the other hand, infected adults more often develop clinically apparent hepatitis and even fulminant hepatic failure, but much less often (5\% to $10 \%$ of cases) develop chronic carrier states. Many but not all chronic HBV carriers (approximately $20 \%$ to $30 \%$ ) eventually die of liver failure and/or hepatocellular carcinoma (HCC). Those at the greatest risk of such outcomes are males, those infected early in life and those residing in areas of the world where exposure to cocarcinogens such as aflatoxins is common; there is a $40 \%$ to $50 \%$ chance the deaths of people in these groups will result directly or indirectly from the consequences of HBV infection (2). While recent advances in immunoprophylaxis and antiviral therapies are expected to decrease this figure significantly, the introduction of such measures to impoverished regions where their need is greatest is a significant challenge to the health care delivery system of those nations.

\section{HBV STRUCTURE}

HBV is a small (42 nm), double-stranded DNA virus belonging to a family of hepatitis DNA viruses called Hepadnaviridae (3). Other well known members of the family include the woodchuck, ground squirrel and duck hepatitis viruses. Although genetically similar, these viruses cannot establish infections in humans. While attempts have been made to extrapolate the natural history of these viruses from infected animals to humans, the very different immune response of the human, combined with the fact that HBV is not inherently virulent but rather induces inflammation and injury through immune-mediated mechanisms, renders such extrapolations tenuous at best. The same argument can be made, although it rarely is, against their use as models for antiviral therapy.

Structurally, the HBV consists of an outer lipoprotein envelope and an inner protein/DNA nucleocapsid. The lipid component of the envelope is derived from the host cell, while the virus itself synthesizes the protein component (4). The protein consists of three related proteins referred to as large (L), middle (M) and small (S) hepatitis B surface antigens ( $\mathrm{HBsAg}$ ). Sequencing of the genes responsible for encoding these proteins has resulted in a relatively new classification system for HBV termed 'HBV genotyping'. To date, six genotypes (A to F) with epidemiological but not clinical relevance have been identified. Genotype A is most common in North America.

Each HBsAg protein (L, M and S) possesses certain functions and properties that are important, if not essential, for viral survival. For example, LHBsAg is thought to contain the binding site required for viral entry into the host hepatocyte $(5,6)$. It is also essential for viral assembly (7). When intracellular levels of LHBsAg are excessive, secretion of intact virus from cells is altered (4). Extremely high levels have been associated with the development of HCC in mice (8). LHBsAg also contains B and T cell epitopes that play a role in the humoral and cellular response to infection (9). Finally, a smaller or 'truncated' version of LHBsAg has the ability to stimulate mRNA synthesis and serve as a 'transcriptional activator', which might be relevant to hepatocarcinogenesis (8).

Fewer functional roles have been identified for MHBsAg. It is clearly not essential for viral assembly, but mutations at the site responsible for its own transcription, the initiation codon, have been described in Mediterranean patients with fulminant hepatic failure and HCC (10-12).

The smallest HBsAg, SHBsAg, is the predominant component of the viral envelope. It contains a hydrophilic region between amino acids 100 and 160 that results in a double-looped structure being displayed on the outer surface of the virus (13). The second loop between amino acids 124 and 147 is conserved in all HBV genotypes and serves as the target for neutralizing antibodies (antibody to HBsAg [anti-HBs]), be they naturally acquired, a result of passive prophylaxis with hepatitis B immunoglobulin (HBIG) or in response to active prophylaxis with HBV vaccine (natural and recombinant) (14).

Encompassed by the viral envelope is the nucleocapsid or core of the virus. The core consists of approximately 200 protein particles that together constitute the hepatitis $\mathrm{B}$ core antigen $(\mathrm{HBcAg})$. Each core particle in turn consists of a large (185 amino acid) and a small (29 amino acid) segment (15).

In addition to capsid formation, core particles are responsible for packaging the mRNA required for viral replication, together with the enzyme involved in the replicative process (16). Other functions of core particles include trafficking of the capsid in the host cell, containment within the viral envelope, and provision of $\mathrm{B}$ and $\mathrm{T}$ cell epitopes that render the core immunogenic to the host (17).

A slightly larger version of core particles is the hepatitis $\mathrm{B}$ e antigen $(\mathrm{HBeAg})$. Whereas the core protein is the translation product of the $\mathrm{C}$ gene, translation from an upstream initiation codon results in a precore protein, which is post-translationally modified at both the $\mathrm{C}$ and $\mathrm{N}$ terminal ends to form the soluble HBeAg. This $17 \mathrm{kD}$ secretory protein is synthesized in concert with viral repli- 
cation and, therefore, serves as a surrogate marker of viral replicative activity (18). It serves the virus by acting as an immune tolerogen, thereby diverting host responses from $\mathrm{HBcAg}$ in the liver toward an innocuous circulating protein. The only structural difference between core and e proteins is that e proteins lack the arginine-rich, 35-amino acid end of the core particle (17). Despite the rather subtle structural difference, it is sufficient to result in two very different host responses; $\mathrm{HBeAg}$ induces a T helper 2 lymphocyte response, while $\mathrm{HBcAg}$ elicits a T helper 1 lymphocyte response and cellular immunity (19).

Although not a structural component of the intact virus, HBV replication is dependent on the synthesis of a unique 832-amino acid enzyme known as DNA polymerase (DNA-P). This enzyme consists of four functional domains. The first domain (residues 1 to 173) primes the viral template, and the second is a nonfunctional 'spacer' domain consisting of 153 amino acids (residues 179 to 336) that separate the priming domain from the third, reverse transcriptase (residues 337 to 630) domain that possesses both RNA - and DNA-dependent polymerase activity (20). This reverse transcriptase domain in turn contains a catalytic domain with five conserved motifs (A to $\mathrm{E}$ ). The fourth domain is the RNase $\mathrm{H}$ domain (residues 681 to 832), which serves to destroy residual viral mRNA resulting from the viral replicative cycle (20).

The smallest HBV protein is the 154-amino acid HBX protein. This protein, which has a low level of expression during the natural history of HBV infection, possesses a variety of properties, including the ability to activate several cellular genes that regulate cell growth (eg, c-jun, c-fos, c-myc, class II and III promoters), induce cell proliferation in quiescent fibroblasts, reduce clonal outgrowth of cells, increase apoptosis (via a p53-dependent pathway) and increase a late $G_{1}$ cell cycle block (21-26). Moreover, HBX not only transforms certain cell types in vitro, but also induces HCC in transgenic mice (27). It should be noted, however, that in some mice exposed to HBX, no pathology occurs, or HBX merely increases their susceptibility to chemical carcinogens and accelerates c-myc-induced HCC but does not act independently of these factors $(28,29)$.

The majority of HBX is cytosolic, but a small portion is active in the nucleus, where it directly interacts with the P53 tumour suppresser and DNA repair factor $(30,31)$. More recently, HBX has been reported to inhibit cellular protein degradation via a serine protease inhibitor domain $(32,33)$.

\section{HBV REPLICATIVE CYCLE}

Many questions remain unresolved with respect to the precise mechanism whereby HBV viral protein synthesis and replication occur. For example, the host cell receptor responsible for HBV entry has yet to be identified, as does how the virus disassembles and translocates to the host nucleus. Once within the nucleus, however, certain events are known to occur (34). One of the earliest is the completion of the incomplete DNA strand that constitutes the double-stranded DNA structure of the viral genome. This event is mediated by a cellular DNA-dependent, RNA polymerase enzyme. The end result is a closed, circular, covalently coiled DNA that is now capable of mRNA synthesis.

Four mRNAs are encoded by the virus. The largest is a $3.5 \mathrm{~kb}$ mRNA known as pregenomic HBV-RNA (pgRNA). Synthesis of this mRNA is under the regulation of a region of the viral genome called the basic core promoter (BCP). pgRNA serves as the template for both $\mathrm{HBcAg}$ and DNA-P synthesis. Another form of the $3.5 \mathrm{~kb}$ transcript - precore mRNA - is also under the control of BCP and is responsible for HBeAg synthesis (35). LHBsAg is derived from a $2.4 \mathrm{~kb}$ pre- $\mathrm{S}_{1}$ mRNA, while two smaller $2.1 \mathrm{~kb}$ mRNAs are responsible for MHBsAg and SHBsAg synthesis, respectively. To date, the $0.7 \mathrm{~kb}$ HBX mRNA has only been described in transfected cell lines $(36,37)$.

When sufficient intracellular levels of all four mRNAs are reached, viral assembly occurs. Within the developing virion, DNA-P binds to pregenomic mRNA and is translocated to the encapsidation signal epsilon, and reverse transcription begins (38). A negative-strand DNA is produced, while RNAse $\mathrm{H}$ of the polymerase protein destroys much of the pgRNA (15 to 18 nucleotides remain to serve as a primer for the subsequent synthesis of the positive DNA strand) (39). The assembled nucleocapsid is then enveloped by the lipoprotein membrane formed from the cell lipid bilayer and viral surface proteins. All but a small amount of the nucleocapsid material required to maintain viral DNA within the host nucleus is exported through an unidentified secretory pathway (40).

\section{HBV SEROLOGY}

The following are the six serological tests most commonly used in clinical practice.

\section{HBsAg}

Historically, the first serological marker to be described in association with HBV infections was $\mathrm{HBsAg}$, or 'Australia antigen'. The presence of this marker in the blood generally indicates the presence of an HBV infection. As discussed above, $\mathrm{HBs} \mathrm{Ag}$ is synthesized and secreted by infected hepatocytes in excess (1000- to 10,000-fold) of the numbers of actual virions produced by the liver; therefore, while its detection indicates the presence of an HBV infection, levels of HBsAg do not necessarily correlate with the extent of viral replication (18). False positive HBsAg results are rare and are largely limited to a small subset of vaccine recipients (typically newborns and dialysis patients) who, for short periods of time after vaccination, may be HBsAg positive but HBV-DNA negative (41). False negative results most commonly occur during the so-called 'window' phase of acute HBV infections, when HBsAg levels are below the detection limits of most assays and antibody to HBsAg has yet to appear. Because individuals in this phase of infection may still be HBV-DNA positive, they should continue to be considered infected and, therefore, potentially infectious to 
others. The window phase of HBV infections can last for weeks and, rarely, years (42). Throughout this period, antibody to $\mathrm{HBcAg}$ (anti-HBc) may serve as the sole indicator of recent HBV infection. Negative HBsAg results, despite the presence of infection, can also occur in HBV-vaccinated infants and in transplant recipients treated with high doses of hepatitis B immunoglobulins (see below).

\section{Anti-HBs}

Just as the presence of HBsAg in the blood generally indicates an HBV infection, anti-HBs indicates immunity to HBV. Whether that immunity was obtained as a result of recovery from a natural infection, or as a response to $\mathrm{HBsAg}$ vaccination or the recent (past three to six months) administration of hepatitis B immunoglobulin can usually be ascertained by questioning the patient and additional serological testing. At some time during chronic $\mathrm{HBV}$ infection, approximately 30\% of HBsAg-positive carriers will have concurrent anti-HBs (43). The anti-HBs in this setting is often present in low titres and is heterotypic, ie, directed toward an HBV subtype other than that in the infected host (44).

\section{Anti-HBc}

Although the 200 core peptides that make up the nucleocapsid of the intact virion are not secreted by hepatocytes in any form other than that encompassed by HBsAg (ie, the intact virion), core proteins referred to as $\mathrm{HBcAg}$ are integrated into hepatocyte cell membranes and thereby induce an anti-HBc response. This response is prompt, and lasts throughout the course of infection and for decades beyond clearance of the virus (18). Thus, the presence of anti-HBc in the circulation indicates that an individual has been infected with HBV sometime in their life. Whether the infection is ongoing or has resolved is determined by the presence or absence of $\mathrm{HBsAg}$ and anti-HBs, respectively. The presence of immunoglobulin $\mathrm{M}$ anti- $\mathrm{HBc}$ generally indicates that infection occurred within the past three to six months; however, positive immunoglobulin $\mathrm{M}$ anti-HBc results can also occur during severe exacerbations of chronic HBV infections (45). False positive and negative anti-HBc results are uncommon (less than $5 \%$ of cases) with modern serological assays.

\section{$\mathrm{HBeAg}$}

An additional antigen used in HBV serological testing is HBeAg. As discussed above, $\mathrm{HBeAg}$ consists of a large amino acid peptide that is synthesized and secreted by hepatocytes in proportion to the extent of viral replication. Thus, the presence and quantity of $\mathrm{HBeAg}$ in the circulation reflect the level of viral replication and, therefore, the degree of infectivity to others (46).

\section{Antibody to $\mathrm{HBeAg}$}

Other than in the setting of precore mutant infections, the presence of antibody to $\mathrm{HBeAg}$ (anti-HBe) generally indicates low levels of HBV replication and low degrees of infectivity (47). Both HBeAg and anti-HBe may be absent during the transition period between active and inactive viral replicative states (47). Concurrent $\mathrm{HBeAg}$ and antiHBe positivity is rare but can be seen during the same transition period.

\section{HBV-DNA}

HBV-DNA testing by relatively insensitive assays (nonpolymerase chain reaction [PCR]-based techniques) is increasingly being used to confirm the presence of HBV infection, determine levels of viral replication/load and predict responses to antiviral agents (48). The clinical relevance of a PCR-positive HBV-DNA test in an HBsAg-negative, anti-HBs-positive individual has yet to be determined.

\section{HBV MUTANTS}

The half-life of HBV in the blood has been estimated to be one day (49). As HBV-DNA levels tend to be relatively constant, given an average viral load, approximately $10^{11}$ HBV particles must be released into the circulation daily (49). Thus, considerable viral replication is presumed to be underway within the liver. With each replicative cycle, the opportunity exists for mutations to occur in the viral genome. Why then, at such a high rate of replicative activity, have more HBV mutants not been recognized? The answer to this important question is almost certainly multifactorial. Two frequently cited explanations follow.

First, many additional mutants exist but have yet to be identified. Indeed, rapid advances in molecular biological techniques have confirmed that a large number of HBV mutants do exist. Moreover, many of these mutants are capable of inducing acute and chronic liver diseases that were previously ascribed to other known or suspected hepatotropic viruses. It should be noted that there are two commonly employed strategies for detecting viral mutants:

1. PCR amplification of the viral genome followed by cloning of the PCR product, selection and sequencing of individual clones, and

\section{PCR amplification and direct sequencing of the PCR} product.

The former cloning strategy provides sequences of only one strain (dominant or not), whereas the latter direct strategy provides a more complete analysis of the overall viral population, although only of the predominant strains (34). Neither strategy provides extensive information about HBV quasispecies, with the clonal assay being limited by the number of clones selected for evaluation. Also relevant to mutation detection is the cross-sectional nature of many studies, wherein the emergence of HBV mutants would not be detected unless a longitudinal study format were in place. Indeed, the distinction between 'mutations' and 'variations' is based on the chronology of the viral form, with mutations being considered nucleotide changes arising in an evolutionary fashion over time and within the same source, whereas variations refer to nucleotide differences 
from the 23 fully sequenced HBV genomes registered in GenBank that are stable over time and within sources (34).

The second, perhaps more relevant, explanation for the perceived paucity of HBV mutants relates to the unique structure of the HBV genome. The compact nature of the genome (Figure 1) defines four overlapping open reading frames (ORF). These ORFs encode the envelope (pre-s/s), core $($ pre-c/c), polymerase and X proteins. The extent of the overlap is such that more than $50 \%$ of the genome is translated by more than one ORF, and every nucleotide is located within at least one coding region (15). Thus, a single mutation in one ORF (eg, pre-s/s) will affect the structure of the overlapping gene product (polymerase enzyme). In many instances, this domino effect renders the virus either replicatively incompetent or incapable of infecting additional hepatocytes (15). In many cases, mutant viruses may also have a reduced fitness, making them inefficient competitors for the wild-type virus. Additional changes may alter immune recognition and clearance. There are numerous possible additional effects. Thus, the dynamics of both replication and clearance are key in evaluating mutant emergence in patients.

On the other hand, there are features of the virus and its replicative cycle that encourage mutation development. One such feature is the lack of proofreading capabilities of the HBV-DNA-P enzyme (50). Proofreading is a mechanism whereby mutations - whether they be point (nucleotide substitutions), insertional or deletional (which cause fatal frame shifts) - are identified by replicative enzymes and either replication ceases or a dysfunctional virus is produced. Unlike RNA viruses, most DNA viruses incorporate cell enzymes that have proofreading capacity; therefore, in general, fewer mutations are tolerated with DNA viral infections. HBV, which uses its own reverse transcriptase/DNA polymerase enzyme, is an exception. The end result is that approximately one in $10^{4}$ nucleotide base misincorporations occur per year (51). If these mutations offered survival advantages over the wild-type virus, such as greater replicative activity, the ability to evade the host's immune response or resistance to antiviral agents, the mutants would persist and might become the predominant viral pathogen of the infected liver.

\section{S mutants}

The target of the host's humoral response to HBV is the hydrophilic region of HBsAg between amino acid residues 100 and 160, the so-called 'a' epitope. Thus, a distinct survival advantage would be afforded to HBV variants with mutation(s) in this (more precisely between amino acid residues 124 and 147) or adjacent regions that interfere with the binding of neutralizing anti-HBs. Because the ' $a$ ' epitope domain is within the RT domain of the DNA-P (whereas pre-S1/S2 domains correspond with the spacer domain of DNA-P), advantageous changes in viral replicative activity might also occur with mutations in this region. Such a mutation was first described in an Italian child who developed an HBV infection, despite having received com-

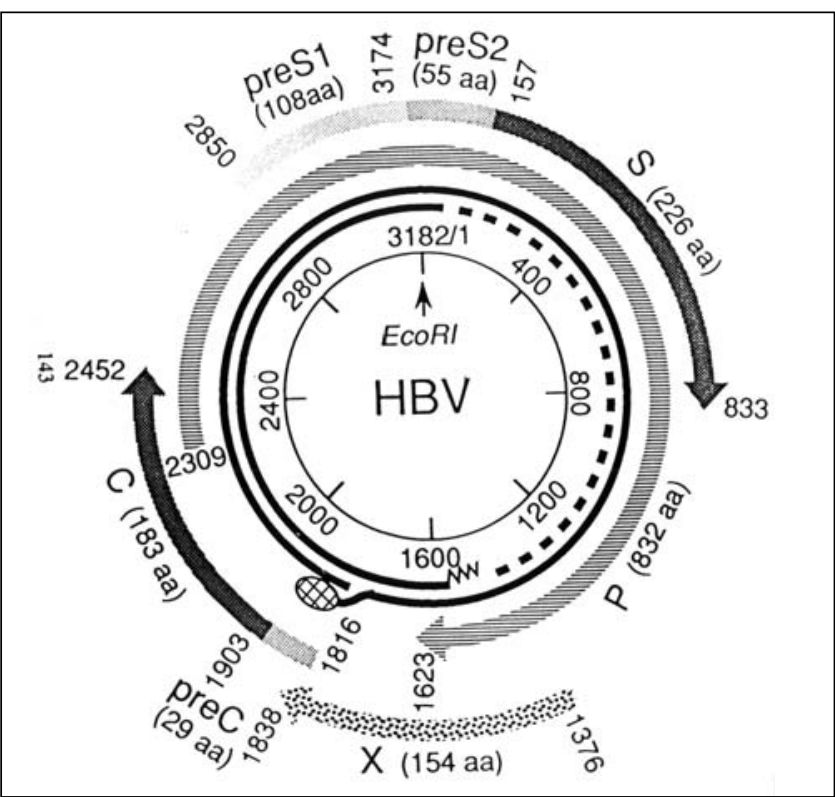

Figure 1) The hepatitis $B$ virus (HBV) genome. aa Amino acid

plete vaccination and $\mathrm{HBIG}$ at birth (52). The mutation resulted in a glycine to arginine switch at amino acid 145. Other common mutations reported in this region include aspartate-144-alanine, methionine-133-leucine, glutamine129-histidine and isoleucine/threonine-126-alanine (53). These mutations have been described in many areas of the world but appear to be most common in Asian infants; in this group, $2 \%$ to $3 \%$ of vaccine recipients at birth were found to have glycine to arginine mutations at this site (53). An increased risk of developing $S$ mutations has been described in infants of mothers with high viral loads and mutations elsewhere in the mother's HBV S gene (54). Glycine to arginine mutations are also common in liver transplant recipients receiving HBIG (53). Less frequently, they develop spontaneously during the course of a chronic HBV infection $(55,56)$.

Some of these mutations, which are often referred to as 'S escape mutants', have been described in association with important clinical events. For example, the threonine-126alanine mutation has been identified in vaccinated infants who subsequently developed fulminant hepatic failure (57). Of more diagnostic concern are nucleotide insertions in the area of amino acids 121 to 124 , which can result in false negative $\mathrm{HBsAg}$ test results and thereby represent a risk to the health of an undiagnosed patient and the safety of the blood transfusion system (55-58).

The study that has most extensively documented the prevalence of $\mathrm{S}$ escape mutants is that reported by Hsu et al (59). Investigators studied approximately 1500 stored sera sampled from children just before universal HBV vaccination in their country (1984), and from similar sized groups of children belonging to the same age groups five and 10 years after the introduction of universal vaccination. The results of the study revealed that the contribution of $S$ escape mutants to the overall prevalence of vaccine failures (HBV- 
DNA-positive children) increased from $7.8 \%$ in 1984 to $19.6 \%$ in 1989 to $23.1 \%$ in 1994 . That vaccination was responsible for the increases was supported by the finding that the mutation rate was $36.4 \%$ in vaccinated children but only $9.9 \%$ in unvaccinated children. Moreover, those with $\mathrm{S}$ escape mutants were younger than those without, suggesting that vaccine-induced pressure resulted in a more rapid emergence of the mutant gentotype. Finally, mutations in the neutralizing region were more common in the 10 -year postuniversal vaccination cohort. Of interest, the absolute numbers of carriers with mutants did not increase over the 10 years of the study (eight of 1200 , nine of 1134 and five of 1515 in the years 1984, 1989 and 1994, respectively), suggesting that, although these mutants constitute an increasing percentage of vaccine failures, they are not becoming more widespread.

The clinical concerns associated with S escape mutants lie in the following four areas.

- Although uncommon, their failure to be detected by commercially available tests for $\mathrm{HBs} \mathrm{Ag}$ raises the possibility that carriers of these mutants could enter the blood donor population (60). In this regard, it is important to note that, in more than $95 \%$ of cases, anti-HBc is and remains strongly positive (59). Other diagnostic tests that can be positive in this setting are HBV-DNA and HBeAg (59).

- Despite encouraging results in vaccinated chimpanzees, HBIG and HBV vaccination does not provide universal or complete protection from infection with these mutants in humans (61). Fortunately, intrafamilial spread of the mutants has yet to be described.

- Like other HBV forms, these mutants have the capacity to induce both acute and chronic liver disease, as well as $\operatorname{HCC}(62,63)$.

- Because mothers of children with $S$ escape mutants need not be HBsAg and/or and anti-HBc positive, and need not have mutants themselves (indeed, more often do not), horizontal as well as vertical transmission appears likely (60).

\section{Precore and core promoter mutants}

More mutations of the viral genome may be tolerated in the large region of the precore/core ORF, which is not overlapped by another ORF. The most common and extensively studied of these is the glycine to arginine point mutation at nucleotide 1896 of the precore region that transforms codon 23 from tyrosine-glycine-glycine to a tyrosine-arginine-glycine stop codon, which terminates transcription at this site and thereby abrogates the synthesis of $\mathrm{HBeAg}$ $(64,65)$. The same mutation also affords the viral genome increased stability as the 1896-nucleotide site that is now occupied by adenine binds more avidly to the corresponding thymidine nucleotide at position 1858 , resulting in enhanced pregenomic encapsulation and initiation of DNA synthesis (66). Presumably, this feature has contributed to precore mutant infections being a very common, if not the most common, form of HBV in the Mediterranean, Africa, Southern Europe and Asia (50\% to 60\% of HBV carriers) $(67,68)$. Although common in these areas, precore mutants are unlikely to become as prevalent in North America, where prevalence figures are in the $10 \%$ to $30 \%$ range (67), because the predominant genotype in North America and Europe is A, which has a cytosine at position 1858 rather than the thymidine nucleotide required to stabilize the arginine base at the corresponding 1896 site (66). The same low prevalence would also be predicted in regions where the F genotype is common, where a thymidine is also lacking at nucleotide 1858. The status of the 1858 nucleotide site may be clinically important in its own right because studies have demonstrated that patients without mutations at position 1896 but a thymidine rather than cytosine nucleotide at position 1858 had greater histological activity/inflammation on liver biopsy $(67,68)$. On the other hand, patients with mutations at position 1896 and thymidine rather than cytosine nucleotides at position $1858 \mathrm{had}$ more benign histological findings (67). It should be noted that not all HBeAg-negative, HBV-DNA-positive patients have the precore mutation at position 1896. A small percentage, estimated at approximately $10 \%$ to $15 \%$, have other mutations, insertions and/or deletions, resulting in frame shifts that explain their $\mathrm{HBeAg}$ negativity (69). Glycine to arginine mutations at nucleotides 1898 and 1899 have also been reported to be associated with the severity of liver disease $(70,71)$.

Although initially described in association with histologically active liver disease, including fulminant hepatic failure, the precore mutant has more recently been identified in chronic HBV carriers without biochemical or histological evidence of liver disease (67). Indeed, in a recent population-based study of Canadian Inuit, none of the approximately 35 precore mutant carriers identified had clinical or biochemical evidence of liver disease (72). Moreover, there are data indicating that reactivation of disease is not associated with the emergence of precore mutants and that wild-type virus is associated with more inflammation and fibrosis than precore mutants (73). Finally, HBV-DNA levels are not increased in patients with precore mutant infections compared with those with wildtype infection $(74,75)$. Thus, the mutation itself is not uniformly pathogenic. These findings have led to searches for comutations that might explain the more virulent forms of precore infections originally described. Strong candidates are point mutations and short deletions or insertions in the core promoter/enhancer II (nucleotide 1634 to 1782) region, which not only limit the transcription of precore mRNA and thereby HBeAg synthesis, but also enhances transcription of core mRNA and with it, $\mathrm{HBcAg}$ and polymerase enzyme synthesis (76). The most frequently described mutations in this region are an arginine to tyrosine nucleotide substitution at nucleotide 1762 and a glycine to arginine substitution at nucleotide 1764 . The existence of mutations at these sites correlates with disease 
progression and has been implicated in hepatocarcinogenesis $(77-79)$. Clinical studies have shown that $30 \%$ of presumably healthy HBV carriers attempting to donate blood had core promoter mutations compared with $90 \%$ to $100 \%$ of patients with active disease, cirrhosis or HCC (80). This increased pathogenicity presumably relates to increased core protein synthesis and viral replication, and decreases the synthesis of the immunotolerogen HBeAg. However, not all studies have identified an association between 1762/1764 mutations and the severity of liver disease (81). Whether precore and/or core promoter mutations predispose the patient to a rapidly progressive fibrosing, cholestatic form of liver disease after liver transplantation is unclear (82-84).

In terms of therapeutic implications, initial reports suggested that, if more than $20 \%$ of the viral population within a patient consists of precore mutants, then a poor response to interferon therapy can be expected (85). On the other hand, more recent data suggest that a high prevalence of precore mutants results in earlier responses to interferon therapy (86). What is clear is that relapses are more common when interferon therapy is withdrawn; however, this may be also be related to associated mutations in the core promoter or core region rather than in the precore region (87). Indeed, the importance of the core promoter region in terms of predicting the response to interferon therapy has recently been emphasized in a report describing that responses can be predicted in approximately $80 \%$ of $\mathrm{HBeAg}$ positive and -negative cases by documenting the presence or absence, respectively, of the core promoter mutation at position 1764 (88). Similar findings (rapid initial responses but high relapse rates in patients with precore mutants) have also been described with nucleoside analogue therapy (89).

\section{$\mathrm{HBcAg}$ mutants}

The most immunodominant epitopes of $\mathrm{HBcAg}$ are between amino acids 50 and 69, and 61 and 85 (90). Mutations in this region have been described in HBV patients with active hepatitis but not during the immunetolerant phase of the infection $(91,92)$. If the mutations, which likely occur as a result of $B$ and $T$ cell pressure on the core antigen, are present before interferon therapy, response to treatment is less likely $(88,93)$. Deletions in the core region have also been described and have been shown to result in decreased cytotoxic $\mathrm{T}$ cell responses and viral replication (94). Similar deletions may play a role in converting an immune-tolerant to an immune-intolerant state and in the progression of acute to chronic HBV infection (95).

\section{DNA-P mutants}

Mutations in the catalytic domain of DNA-P are not detected normally but have been described in association with nucleoside analogue therapy (96). In the case of lamivudine, the first nucleoside analogue licensed for the treatment of HBV, a methionine-552-isoleucine or methionine-552-valine mutation in the conserved tyrosine-methionine-aspartate-aspartate' (YMDD) motif that comprises part of the active site (domain C) of the reverse transcriptase has been described, often in association with an upstream leucine-528-methionine substitution (97). Famciclovir, another nucleoside analogue with anti-HBV properties, can induce valine-521-leucine and leucine-528-methionine mutations within the B domain of DNA-P (98). These mutations decrease but do not eliminate the affinity of nucleoside analogues for the DNA-P enzyme. As a result, with the development of these mutations, viral replication increases, but not to levels documented before initiation of treatment (99-101). Because the mutant virus is replicatively compromised in the vital region of DNA-P activity, wild-type virus returns on cessation of drug therapy $(102,103)$.

Of interest, the ' $\mathrm{a}$ ' determinant is located in the variable linker region between the A (410 to 426) and B (498 to 528) domains of DNA-P. Thus, while YMDD mutations could result in $\mathrm{HBs} A g$ changes, they are unlikely to do so in the critical antigenic site of HBsAg. Nonetheless, patients with both YMDD and $S$ escape mutations have been described (104).

\section{HBX mutations}

Data are only just emerging on mutations in the X ORF, which overlap with precore stop codon mutants and BCP mutants. Preliminary findings describe a novel class of HBX mutants in Asian patients with HCC (105). These mutations were found to negate $\mathrm{X}$-induced inhibition of clonal outgrowth and increase apoptosis. Thus, $\mathrm{X}$ mutants increased clonal outgrowth and decreased apoptosis, suggesting a possible carcinogenic role. While this is an intriguing hypothesis, it should be noted the HCC tissue sources for the HBX mutations detected also contained $\mathrm{HBs}$ Ag mutations, which may have been relevant to HCC development (106).

\section{CONCLUSIONS}

Available data allow the following conclusions to be made regarding the $\mathrm{S}$ escape mutant.

- The mutants constitute an increasing percentage of 'vaccine failures', but their prevalence in the general population does not appear to be increasing.

- The overall prevalence in HBV-vaccinated Southeast Asian children born of HBV carrier mothers appears to be low (1\% to $2 \%)$.

- Most often, these mutations are associated with the following serological profile: $\mathrm{HBsAg}$, anti-HBs positive and anti-HBc positive. However, they can also exist as HBsAg negative, anti-HBs positive and anti-HBc positive or anti-HBc positive alone.

- S escape mutants can be associated with active viral replication (approximately 50\% are $\mathrm{HBeAg}$ positive).

- Although precise figures are not yet available, these mutants can be associated with acute and chronic liver disease.

- Passive and active HBV immunity is unlikely to be protective against these mutants. 
Regarding the precore/core promoter mutants:

- It is possible that the majority of precore mutants represent the natural evolution of chronic HBV infections.

- Worsening liver disease is more likely to be associated with core promoter rather than precore mutations.

- The natural history of acute precore/core promoter mutations is unclear.

- HBV-DNA levels tend to increase when core promoter mutations exist.

Regarding core mutants:

- Mutations to the core gene are less common than mutations in other areas of the viral genome.

- Core mutants appear to be associated with viral escape from immune surveillance and are relevant to the response (or lack thereof) to interferon therapy.

Regarding DNA-P mutations:

- DNA-P mutations are uncommon in the absence of nucleoside or nucleotide analogue therapy.

\section{REFERENCES}

1. Margolis HS, Alter MJ, Hadler SC. Hepatitis B: Evolving epidemiology and implications for control. Semin Liver Dis 1991;11:84-92.

2. Blumberg BS. The hepatitis B virus. Public Health Rep 1980;95:427-35.

3. Tiollais P, Charnay P, Vyas GN. Biology of hepatitis B virus. Science 1981;213:406-11.

4. Bruss V, Gerhardt E, Vieluf K, et al. Functions of the large hepatitis B virus surface protein in viral particle morphogenesis. Intervirology 1996;39:23-31.

5. Pontisso P, Ruvoletto MG, Gerlich WH, et al. Identification of an attachment site for human liver plasma membranes on hepatitis B virus particles. Virology 1989;173:522-30.

6. Bruss V. A short linear sequence in the pre-S domain of the large hepatitis $B$ virus envelope protein required for virion formation. J Virol 1997;71:9350-7.

7. Ganem D. Assembly of hepadnaviral virions and subviral particles. Curr Top Microbiol Immunol 1991;168:61-83.

8. Hildt E, Saher G, Bruss V, et al. The hepatitis B virus large surface protein (LHBs) is a transcriptional activator. Virology 1996;225:235-9.

9. Gerlich WH, Deepen R, Heermann KH, et al. Protective potential of hepatitis $B$ virus antigens other than the $S$ gene protein. Vaccine 1990;8:63-8.

10. Gerken G, Kremsdorf D, Capel F, et al. Hepatitis B defective virus with rearrangements in the preS gene during chronic HBV infection. Virology 1991;183:555-65.

11. Fernholz D, Stemler M, Brunetto M, et al. Replicating and virion secreting hepatitis B mutant virus unable to produce preS2 protein. J Hepatol 1991;13:102-4.

12. Pollicino T, Zanetti AR, Cacciola I, et al. Pre-S2 defective hepatitis B virus infection in patients with fulminant hepatitis. Hepatology 1997;26:495-9.

13. Bruss V, Lu X, Thonssen R, et al. Post-translational alterations in transmembrane topology of the hepatitis $B$ virus large envelope protein. EMBO J 1994;13:2273-9.

14. Carman WF, Van Deursen FJ, Mimms LT, et al. The prevalence of surface antigen variants of hepatitis $B$ virus in Papua New Guinea, South Africa, and Sardinia. Hepatology 1997;26:1658-66.

15. Miller RH, Kaneko S, Chung CT, et al. Compact organization of the hepatitis B virus genome. Hepatology 1989;9:322-7.
- The detection of these mutants in patients increases to approximately $50 \%$ after three years of continuous antiviral therapy.

- Although DNA-P mutations decrease the affinity of DNA-P for nucleoside/nucleotide analogue binding, a complete loss of antiviral effect is not observed.

- Finally, DNA-P mutations in the B and C catalytic domains are unlikely to significantly alter the dominant $S$ epitope.

Regarding HBX mutants:

- Mutations in HBX may be associated with an increased risk of HCC.

-The same mutations hold promise as a marker of those HBV carriers who might be at risk of developing $\mathrm{HCC}$ in the future.

ACKNOWLEDGEMENTS: The author thanks Dr Tony Giulivi for his review of the manuscript and the Blood Borne Pathogens Division, Bureau of Infectious Diseases for its support. The author also thanks Mrs S Zdanuk for her prompt and accurate typing of the manuscript. A portion of this review was published in the Canadian Communicable Disease Report.

16. Koschel M, Thomssen R, Bruss V. Extensive mutagenesis of the hepatitis $\mathrm{B}$ virus core gene and mapping of mutations that allow capsid formation. J Virol 1999;73:2153-60.

17. Weimer T, Salfeld J, Will H. Expression of the hepatitis B virus core gene in vitro and in vivo. J Virol 1987;61:3109-13.

18. Hoofnagle JH, Bisceglie AM. Serologic diagnosis and acute and chronic viral hepatitis. Semin Liver Dis 1991;11:73-83.

19. Pumpens P, Grens E. Hepatitis B core particles as a universal display model: a structure-function basis for development. FEBS Lett 1999;442:1-6.

20. Poch O, Sauvaget I, Delarus M, et al. Identification of four conserved motifs among the RNA-dependent polymerase encoding elements. EMBO J 1989;8:3867-74.

21. Feitelson MA, Duan LX. Hepatitis B virus X antigen in the pathogenesis of chronic infections and the development of hepatocellular carcinoma. Am J Pathol 1997;150:1141-57.

22. Twu JS, Lai MY, Chen DS, et al. Activation of protooncogene c-jun by the X protein of hepatitis B virus. Virology 1993;192:346-50.

23. Lee WM. Hepatitis B virus infection. N Engl J Med 1997;337:1733-45.

24. Runkel L, Fischer M, Schaller H. Two-codon insertion mutations of the HBx define two separate regions necessary for its trans-activation function. Virology 1993;197:529-36.

25. Gottlob K, Pagano S, Levrero M, et al. Hepatitis B virus X protein transcription activation domains are neither required nor sufficient for cell transformation. Cancer Res 1998;58:3566-70.

26. Koike K, Takada S. Biochemistry and functions of hepatitis B virus X protein. Intervirology 1995;38:89-99.

27. Koike K, Moriya K, Iino S, et al. High-level expression of hepatitis B virus $\mathrm{HBx}$ gene and hepatocarcinogenesis in transgenic mice. Hepatology 1994;19:810-9.

28. Slagle B, Lee T, Medina D, et al. Increased sensitivity to the hepatocarcinogen diethylnitrosamine in transgenic mice carrying the hepatitis B virus X gene. Mol Carcinogen 1996;15:261-9.

29. Terradillos $\mathrm{O}$, Billet $\mathrm{O}$, Renard $\mathrm{C}$, et al The hepatitis $\mathrm{B}$ virus $\mathrm{X}$ gene potentiates c-myc-induced liver oncogenesis in transgenic mice. Oncogene 1997;14:395-404.

30. Sirma H, Wiel R, Rosmorduc O, et al. Cytosol is the prime compartment of hepatitis B virus X protein where it colocalizes with the proteasome. Oncogene 1998;16:2051-63.

31. Doria M, Klein N, Lucito R, et al. The hepatitis B virus HBx protein is a dual specificity cytoplasmic activator of Ras and nuclear activator of transcription factors. EMBO J 1995;15:4747-57. 
32. Fischer M, Runkel L, Schaller H. HBx protein of hepatitis B virus interacts with the $\mathrm{C}$-terminal portion of a novel human proteasome alpha-subunit. Virus Genes 1995;10:99-102.

33. Huang J, Kwong J, Sun ECY, et al. Proteasome complex as a potential cellular target of hepatitis B virus X protein. J Virol 1996;70:5582-91.

34. Torre F, Naoumov NV. Clinical implications of mutations in the heptitis B virus genome. Eur J Clin Invest 1998;28:604-14.

35. Schlicht HJ, Radziwill G, Schaller H. Synthesis and encapsidation of duck hepatitis B virus versus reverse transcriptase do not require formation of core-polymerase fusion proteins. Cell 1989;56:85-92.

36. Will H, Reiser W, Weimter T, et al. Replication strategy of human hepatitis B virus. J Virol 1987;61:904-11.

37. Koike K, Akatsuka T, Miyamura T. Characterization of hepatitis B virus $\mathrm{X}$ gene: in vitro translation of mRNA from COS-1 cells transfected with the X gene. Virology 1988;163:233-5.

38. Nassal M, Schaller H. Hepatitis B replication - an update. J Viral Hepat 1996;3:217-26.

39. Loeb DD, Hirsch RC, Ganem D. Sequence-independent RNA cleavages generate the primers for plus strand DNA synthesis in hepatitis B viruses: implications for other reverse transcribing elements. EMBO J 1991;10:3533-340.

40. Nassal M, Schaller H. Hepatitis B replication. Trends Microbiol 1993;1:221-8.

41. Janzen L, Minuk GY, Fast M, et al. Vaccine-induced hepatitis B surface antigen positivity in hemodialysis patients: incidental and surveillance data. J Am Soc Nephrol 1996;7:1228-34.

42. Herrera JL. Serologic diagnosis of viral hepatitis. South Med J 1994;87:677-84.

43. Shiels MT, Taswell HF, Czaja AJ, et al. Frequency and significance of concurrent hepatitis B surface antigen and antibody in acute and chronic hepatitis B. Gastroenterology 1987;93:675-80.

44. Sasaki T, Ohkubo Y, Yamashita Y, et al. Co-occurrence of hepatitis B surface antigen of a particular subtype and antibody to a heterologous subtypic specificity in the same serum. J Immunol 1976;117:2258-9.

45. Sjogren M, Hoofnagle JH. Immunoglobulin M antibody to hepatitis B core antigen in patients with chronic type B hepatitis. Gastroenterology 1985;889:252-8.

46. McAuliffe VJ, Purcell RH, Le Bouvier G. e: A third hepatitis B antigen? N Engl J Med 1976;294:779-80.

47. Hoofnagle JH, Dusheiko GM, Seeff LB, et al. Seroconversion from hepatitis $\mathrm{B}$ e antigen to antibody in chronic type B hepatitis. Ann Intern Med 1981;94:744-8.

48. Perrillo RP, Schiff E, Davis GL, et al. A randomized controlled trial of interferon alpha-2b alone and after prednisone withdrawal for the treatment of chronic hepatitis B. N Engl J Med 1990;323:295-301.

49. Nowak MA, Bonhoeffer S, Hill AM, et al. Viral dynamics in hepatitis B virus infection. Proc Natl Acad Sci USA 1996;93:4398-402.

50. Steinhauer DA, Holland JJ. Rapid evolution of RNA viruses. Annu Rev Microbiol 1987;41:409-33.

51. Girones R, Miller RH. Mutation rate of the hepadnavrius genome. Virology 1989;170:595-7.

52. Carman WF, Zanetti AR, Karayiannis P et al. Vaccine-induced escape mutant of hepatitis B virus. Lancet 1990;336:325-9.

53. Hunt CM, McGill JM, Allen MI, et al. Clinical relevance of hepatitis B viral mutations. Hepatology 2000;31:1037-44.

54. Carman WF. The clinical significance of surface antigen variants of hepatitis B virus. J Viral Hepatol 1997;4:11-20.

55. Yamamoto K, Horikita M, Tsuda F, et al. Naturally occurring escape mutants of hepatitis $B$ virus with various mutations in the $S$ gene in carriers seropositive for antibody to hepatitis B surface antigen. J Virol 1994;68:2671-6.

56. Carman WF, Korula J, Wallace L, et al. Fulminant reactivation of hepatitis $\mathrm{B}$ due to envelope protein mutant that escaped detection by mono-clonal HBsAg ELISA. Lancet 1995;345:1406-7.

57. Hou J, Karayiannis P, Waters J, et al. A unique insertion in the S gene of surface antigen-negative hepatitis $\mathrm{B}$ virus Chinese carriers. Hepatology 1995;21:273-8.

58. Wallace LA, Carman WF. Surface gene variation of HBV: Scientific and medical relevance. Viral Hepatol 1997;3:5-16.

59. Hsu HY, Chang MH, Liaw SH, et al. Changes of hepatitis B surface antigen variants in carrier children before and after universal vaccination in Taiwan. Hepatology 1999;30:1312-7.

60. Coleman PF, Chen YC, Mushahwar IK. Immunoassay detection of hepatitis B surface antigen mutants. J Med Virol 1999;59:19-24.
61. Ogata N, Cote PJ, Zanetti AR, et al. Licensed recombinant hepatitis $B$ vaccines protect chimpanzees against infection with the prototype surface gene mutant of hepatitis B virus. Hepatology 1999;30:779-86.

62. Ogata N, Zanetti AR, Yu M, et al. Infectivity and pathogenicity in chimpanzees of a surface gene mutant of hepatitis B virus that emerged in a vaccinated infant. J Infect Dis 1997;175:511-23.

63. Carman WF, Korula J, Wallace L, et al. Fulminant reactivation of hepatitis $\mathrm{B}$ due to envelope protein mutant that escaped detection by monoclonal HBsAg ELISA. Lancet 1995;345:1406-7.

64. Brunetto MR, Stemler M, Schodel F, et al. Identification of HBV variants which cannot produce precore derived $\mathrm{HBeAg}$ and may be responsible for severe hepatitis. Ital J Gastroenterol 1989;21:151-4.

65. Carman WF, Jacyna MR, Hadziyannis S, et al. Mutation preventing formation of hepatitis B e antigen in patients with chronic hepatitis B infection. Lancet 1989;ii:588-91.

66. Lok AS, Akara U, Greene S. Mutations in the pre-core region of hepatitis B virus serve to enhance the stability of the secondary structure of the pre-genome encapsidation signal. Proc Natl Acad Sci USA 1994;91:4077-81.

67. Lindh M, Horal P, Dhillon AP, et al. Hepatitis B virus carriers without precore mutations in hepatitis $\mathrm{B}$ e antigen-negative stage show more severe liver damage. Hepatology 1996;24:494-501.

68. Chan HLY, Leung NW, Hussain M, et al. Hepatitis B e antigennegative chronic hepatitis B in Hong Kong. Hepatology 2000;31:763-8.

69. Carman WF, Hadziyannis S, McGarvey MJ, et al. Mutation preventing formation of hepatitis $\mathrm{B}$ e antigen in patients with chronic hepatitis B infection. Lancet 1989;11:588-890.

70. Tillmann $\mathrm{H}$, Trautwein $\mathrm{C}$, Walker D, et al. Clinical relevance of mutations in the precore genome of the hepatitis B virus. Gut 1995;37:568-73.

71. Brunetto MR, Stemmler M, Schodel F, et al. Identification of HBV variants which cannot produce precore-derived $\mathrm{HBeAg}$ and may be responsible for severe hepatitis. Ital J Gastroenterol 1989;21:151-4.

72. Minuk GY, Orr PS, Brown R, et al. Pre-core mutant infections in the Canadian Inuit. J Hepatol 2000;33:781-4.

73. Loriot MA, Marcellian P, Talbodec N, et al. Low frequency of precore hepatitis $\mathrm{B}$ virus mutants in anti-hepatitis $\mathrm{B}$ e-positive reactivation after loss of hepatitis B e antigen in patients with chronic hepatitis B. Hepatology 1995;21:627-31.

74. Knoll A, Rohrhofer A, Kochanowski B, et al. Prevalence of precore mutants in anti-HBe-positive hepatitis B virus carriers in Germany. J Med Virol 1999;59:14-8.

75. Brunetto MR, Rodriguez UA, Bonino F. Hepatitis B virus mutants. Intervirology 1999;42:69-80.

76. Li J, Buckwold VE, Hon MW, et al. Mechanism of suppression of hepatitis B virus precore RNA transcription by a frequent double mutation. J Virol 1999;73:1239-44.

77. Fang ZL, Ling R, Wang SS, et al. HBV core promoter mutations prevail in patients with hepatocellular carcinoma from Guangxi, China. J Med Virol 1998;56:18-24.

78. Baptista M, Kramvis A, Kew MC. High prevalence of 1762T 1764A mutations in the basic core promoter of hepatitis B virus isolated from black Africans with hepatocellular carcinoma compared with asymptomatic carriers. Hepatology 1999;29:946-53.

79. Chao SW, Shin YJ, Hahm KB, et al. Analysis of the precore and core promoter DNA sequence in liver tissues from patients with hepatocellular carcinoma. J Korean Med Sci 1999;14:424-30.

80. Takahashi K, Aoyama K, Ohno N, et al. The precore/core promoter mutation of hepatitis B virus: clinical significance and an easy method of detection. J Gen Virol 1995;75:3159-64.

81. Chan HLY, Hussain M, Lok ASF. Different hepatitis B virus genotypes are associated with different mutations in the core promoter and precore regions during hepatitis $\mathrm{B}$ e antigen seroconversion. Hepatology 1999;29:976-84.

82. McMillan JS, Bowden DS, Angus PW, et al. Mutations in the hepatitis B virus precore/core gene and core promoter in patients with severe recurrent disease following liver transplantation. Hepatology 1996;24:1371-8.

83. Protzer U, Goergen B, Hopf U, et al. Pre-core mutants of hepatitis B virus in patients receiving immunosuppressive treatment after orthotopic liver transplantation. J Med Virol 1996;50:135-44.

84. Naumann U, Protzer Knolle U, Berg T et al. A pretransplant infection with precore mutants of hepatitis B virus does not influence the outcome of orthotopic liver transplantation in patients on high dose anti-hepatitis $B$ virus surface antigen immunophrophylaxis. Hepatology 1997;26:478-84. 
85. Brunetto MR, Giarin M, Saracco G, et al. Hepatitis B virus unable to secrete e antigen and response to interferon in chronic hepatitis $\mathrm{B}$. Gastroenterology 1993;105:845-50.

86. Lok AS, Akarca US, Greene S. Predictive value of precore hepatitis $B$ virus mutations in spontaneous and interferon-induced hepatitis B e antigen clearance. Hepatology 1995;21:19-24.

87. Naoumov NV, Thomas MG, Mason AL, et al. Genomic variations in the hepatitis B core gene: a possible factor influencing response to interferon alfa treatment. Gastroenterology 1995;108:505-14.

88. Erhardt A, Reineke U, Blondin D, et al. Mutations of the core promoter and response to interferon treatment in chronic replicative hepatitis B. Hepatology 2000;31:716-25.

89. Tassopoulos NC, Volpes R, Pastore G, et al. Efficacy of lamivudine in patients with hepatitis $B$ e antigen-negative/hepatitis B virus DNApositive (precore mutant) chronic hepatitis B. Lamivudine precore mutant study group. Hepatology 1999;29:889-96.

90. Colucci G, Beazer Y, Cantaluppi C, et al. Identification of major hepatitis $\mathrm{B}$ core antigen determinant by using synthetic peptides and monoclonal antibodies. J Immunol 1988;141:4376-80.

91. Chuang WL, Omata M, Ehata T, et al. Precore mutations and core clustering mutations in chronic hepatitis B virus infection. Gastroenterology 1993;104:263-71.

92. Bozkaya H, Akarca US, Ayola B, et al. High degree of conservation in the hepatitis $B$ virus core gene during the immune tolerant phase in perinatally acquired chronic hepatitis B virus infection. J Hepatol 1997;26:508-6.

93. Bozkaya H, Ayola B, Lok AS. High rate of mutations in the hepatitis $B$ core gene during the immune clearance phase of chronic hepatitis B virus infection. Hepatology 1996;24:32-7.

94. Ackrill AM, Naoumov NV, Eddleston ALWF, et al. Specific deletions in the hepatitis $B$ virus core open reading frame in patients with chronic active hepatitis B. J Med Virol 1993;41:165-9.

95. Akarca US, Lok AS. Naturally occurring hepatitis B virus core gene mutations. Hepatology 1995;22:50-60.
96. Locarnini S, Birth B. Antiviral chemotherapy for chronic hepatitis B infection: lessons learned from treating HIV-infected patients. J Hepatol 1999;30:536-50.

97. Allen MI, Deslauriers M, Andrews CW, et al. Identification and characterization of mutations in hepatitis B virus resistant to lamivudine. Lamivudine Clinical Investigation Group. Hepatology 1998;27:1670-7.

98. Aye TT, Bartholomeusz AI, Shaw T, et al. Hepatitis B virus polymerase mutations during famciclovir therapy in patients following liver transplantation. Hepatology 1996;24:285A. (Abst)

99. Lai CL, Chien RN, Leung N, et al. A one-year trial of lamivudine for chronic hepatitis B. N Engl J Med 1998;339:61-8.

100. Dienstag J, Schiff E, Wright TL, et al. Lamivudine as initial treatment for chronic hepatitis B in the United States. N Engl J Med 1999;341:1256-63.

101. Liaw YF, Chien RN, Yeh CT, et al. Acute exacerbation and hepatitis $B$ virus clearance after emergence of YMDD motif mutation during lamivudine therapy. Hepatology 1999;30:567-72.

102. Rosenberg PM, Dienstag JL. Therapy with nucleoside analogues for hepatitis B virus infection. Clin Liver Dis 1999;3:349-61.

103. Chayama K, Suzuki Y, Kobayashi M, et al. Emergence and takeover of YMDD motif mutant hepatitis B virus during long-term lamivudine therapy and re-takeover by wild type after cessation of therapy. Hepatology 1998;27:1711-6.

104. Oon CJ, Chen WN, Lim N, et al. Hepatitis B virus variants with lamivudine-related mutations in the DNA polymerase and the 'a' epitope of the surface antigen are sensitive to ganciclovir. Antiviral Res 1999;41:113-8.

105. Sirma H, Giannini C, Poussin K, et al. Hepatitis B virus X mutants, present in hepatocellular carcinoma tissue abrogate both the antiproliferative and transactivation effects of $\mathrm{HBx}$. Oncogene 1999;18:4848-59.

106. Oon CJ, Chen WN, Zhao Y, et al. Detection of hepatitis B surface antigen mutants and their integration in human hepatocellular carcinoma. Cancer Lett 1999;136:95-9. 


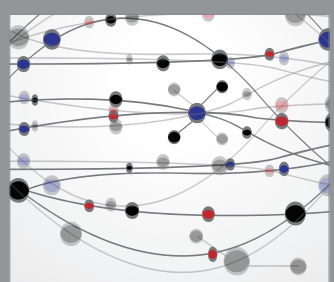

The Scientific World Journal
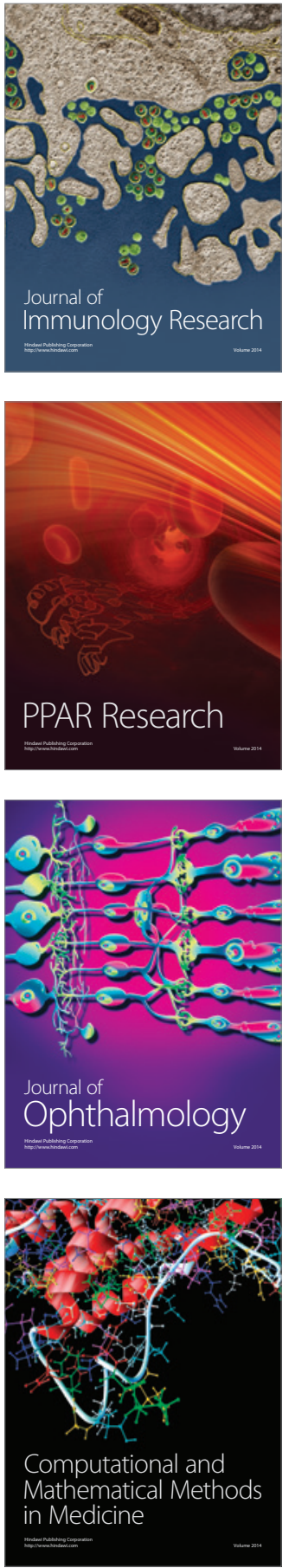

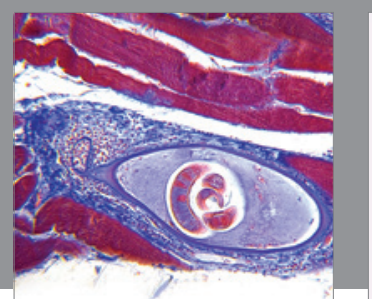

Gastroenterology Research and Practice

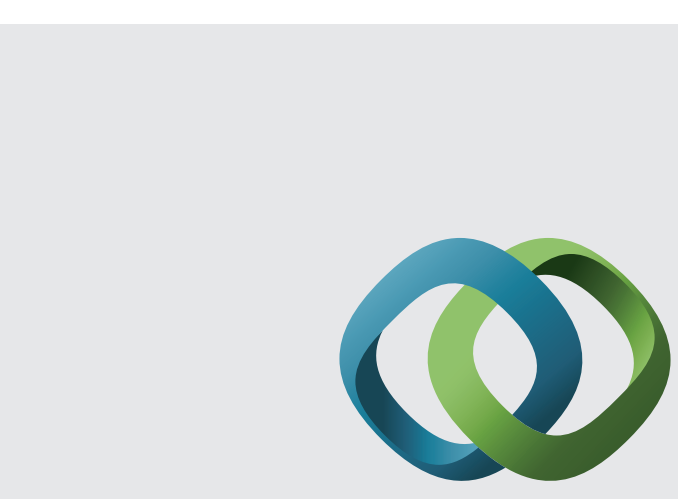

\section{Hindawi}

Submit your manuscripts at

http://www.hindawi.com
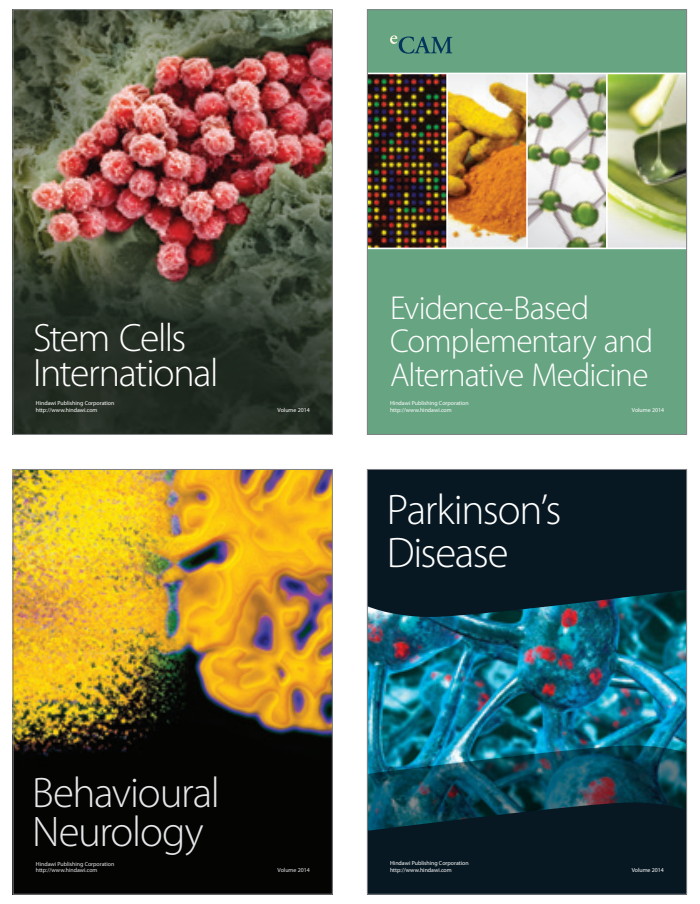
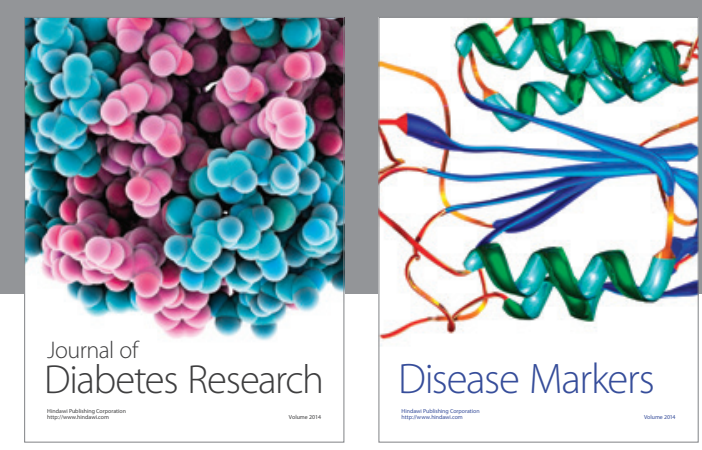

Disease Markers
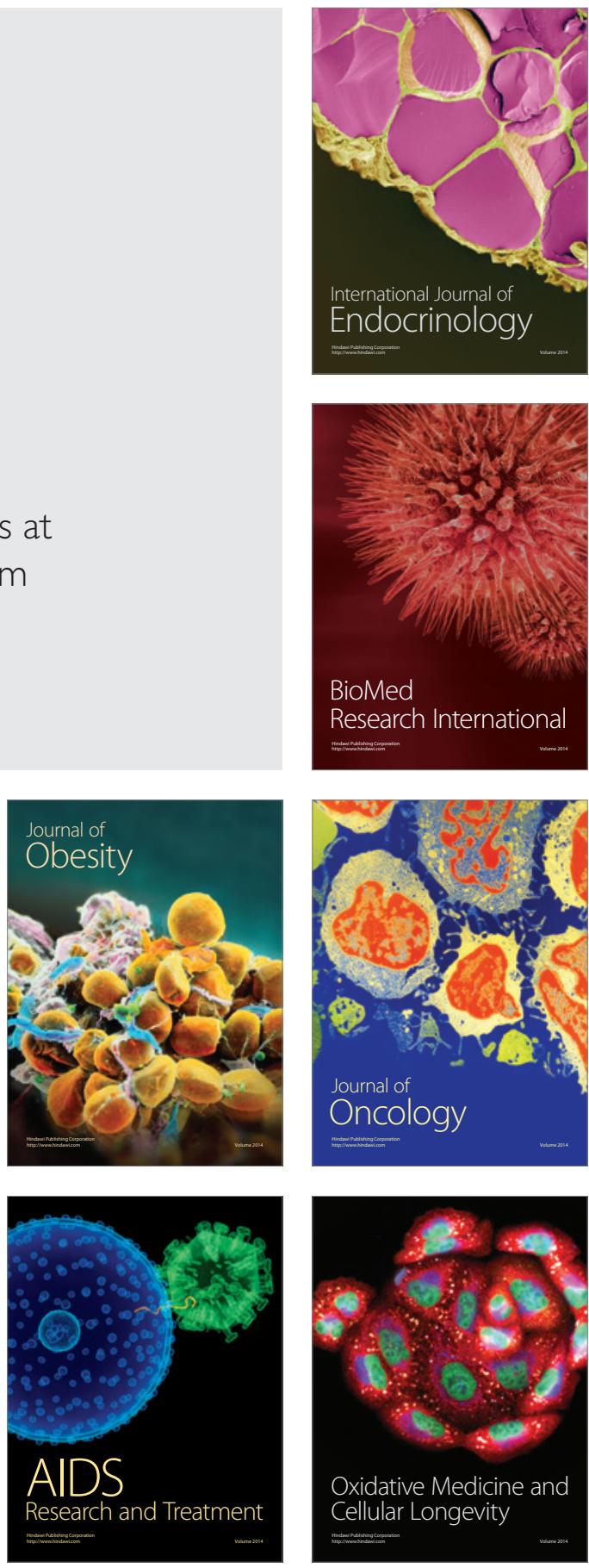